\title{
DERECHOS DE LAS PERSONAS LGBTI EN EL ESTABLECIMIENTO PENITENCIARIO Y CARCELARIO DE VILLAVICENCIO (2015)*
}

\author{
Yudy Andrea Carrillo Cruz
}

Fecha de recepción: 11 de agosto de 2015

Fecha de evaluación: 10 de noviembre de 2015

Fecha de aprobación: 28 de enero de 2016

Artículo de investigación

DOI: http://dx.doi.org/10.18359/prole.1967

Forma de citación: Carrillo, Y. (2016). Derechos de las personas LGBTI en el Establecimiento Penitenciario y Carcelario de Villavicencio (2015). Revista Prolegómenos Derechos y Valores, 19, 38, 11-24. DOI: http://dx.doi.org/10.18359/ prole.1967

\section{Resumen}

La jurisprudencia en Colombia ha otorgado mayores garantías a los derechos de las personas transexuales privadas de la libertad en centros carcelarios y penitenciarios. En este artículo se presentan los resultados de la investigación llevada a cabo en el Establecimiento Penitenciario y Carcelario de Villavicencio, Meta, donde se estudió la manera como las personas transexuales ejercen sus derechos y si debería existir un pabellón especial para ellas. La metodología fue descriptiva, con enfoque cualitativo y analítico. Participaron cuatro personas de las 16 identificadas en la institución como población LGBTI, siendo una mujer homosexual, una mujer travesti, un hombre homosexual y un hombre travesti. El resultado principal arrojó que, por ahora, no es necesaria la creación de un pabellón especial para transexuales y que cada vez hay mayor tolerancia con la comunidad LGBTI dentro del establecimiento carcelario.

\section{Palabras clave:}

Derechos de los internos, homosexualidad, tipos de instituciones carcelarias, transexualidad, sistema penitenciario.

\footnotetext{
Artículo resultado de la investigación "El ejercicio de los derechos de las personas transexuales en el Centro Penitenciario y Carcelario de Villavicencio" desarrollada en la Universidad Cooperativa de Colombia (sede Villavicencio) con el aval del Grupo de Investigación Abogados Solidarios UCC del programa de Derecho, línea violencia y sociedad. Inició en junio de 2014 y finalizó en junio de 2015. En la ejecución del proyecto de investigación participaron los estudiantes Nohora Angélica Herrera González, Marla Karol Zabala Piedrahita y José Avelino Flores.

** Abogada. Maestranda en Derecho Administrativo Universidad Libre (Bogotá, Colombia). Líder del Grupo de Investigación Abogados Solidarios UCC. Profesora auxiliar de la Universidad Cooperativa de Colombia (sede Villavicencio). Correo electrónico: yudy.carrillo@campusucc.edu.co
} 


\title{
RIGHTS OF LGBTI PEOPLE IN THE PENITENTIARY AND PRISON ESTABLISHMENT OF VILLAVICENCIO (2015)
}

\begin{abstract}
Summary
Case law in Colombia has granted more guarantees for the rights of transsexual persons deprived of their liberty in prisons and correctional centers. This article presents the results of the research carried out in the penitentiary and prison of Villavicencio, Meta, where it was studied the way that transsexual people exercise their rights and if there should be a special pavilion for them. The methodology was descriptive, with a qualitative and analytical approach. Four people of the 16 identified in the institution as LGBTI people participated being a homosexual woman, a transvestite female, a gay man and a transvestite male. The main result showed that, for now, it is not necessary the creation of a special transgender pavilion and there is increasingly greater tolerance with the LGBTI community within the prison facility.
\end{abstract}

\section{Keywords:}

Rights of inmates, homosexuality, types of prison institutions, transsexuality, penitentiary system.

\section{DIREITOS DAS PESSOAS LGBTI NO ESTABELECIMENTO PENITENCIÁRIO E CARCERÁRIO DE VILLAVICENCIO (2015)}

\begin{abstract}
Resumo
A jurisprudência na Colômbia outorgou maiores garantias aos direitos das pessoas transexuais privadas de liberdade em centros carcerários e penitenciários. Neste artigo é apresentado os resultados da pesquisa realizada no Estabelecimento Penitenciário e Carcerário de Villavicencio, Meta, onde foi estudada a maneira como as pessoas transexuais exercem os seus direitos e se deveria existir um pavilhão especial para elas. A metodologia foi descritiva, com enfoque qualitativo e analítico. Participaram quatro pessoas das 16 identificadas na instituição como população LGBTI, sendo uma mulher homossexual, uma mulher travesti, um homem homossexual e um homem travesti. O resultado principal mostrou que, por enquanto, não é necessária a criação de um pavilhão especial para transexuais e que cada vez há maior tolerância com a comunidade LGBTI dentro do estabelecimento carcerário.
\end{abstract}

\section{Palavras-chave:}

Direitos dos internos, homossexualidade, tipos de instituições carcerárias, transexualidade, sistema penitenciário.

\section{Introducción}

En la presente investigación la autora partió de la premisa de que el sistema penitenciario, tal como está concebido en la actualidad, solamente diferencia entre hombres y mujeres, disponiendo de centros de reclusión para estos dos tipos de género, mas no tiene en cuenta a transexuales. La pregunta de investigación consistía en saber si en el Establecimiento Penitenciario y Carcelario de Villavicencio se respetan los derechos de las personas transexuales allí recluidas y entre los objetivos que se formularon, estaba comprobar si en este lugar debería existir un pabellón especial 
para las personas transexuales y la manera como ellos ejercen sus derechos al interior del centro carcelario, teniendo en cuenta la legislación y la jurisprudencia de la Corte Constitucional.

La investigación se desarrolló en el Establecimiento Penitenciario y Carcelario de Villavicencio, capital del departamento del Meta, ubicada en el piedemonte de la cordillera Oriental, al noroccidente del departamento.

De acuerdo con datos aportados por la entidad, para el 12 de junio de 2015, el sistema Sisipec web, del Instituto Nacional Penitenciario y Carcelario (Inpec) registró que la población de internos se conformaba por 1552 hombres y 147 mujeres, para un total de 1699 presos $^{1}$, de los cuales 16 pertenecen a población lesbiana, gay, bisexual, transgénero e intersexual (LGBTI) (Inpec, 2015).

Lo primero que se hizo al iniciar la investigación fue una indagación para establecer si existían estudios en el Establecimiento Penitenciario y Carcelario de Villavicencio, relacionados con el ejercicio de los derechos de las personas transexuales recluidas en esta prisión y el modo como los hacen efectivos estando allí. Sin embargo, no se encontraron investigaciones al respecto.

\section{A. Metodología}

La investigación utilizó una metodología descriptiva, jurídica, con enfoque cualitativo y analítico, y el método de estudio fue inductivo.

\section{Población participante}

Internos de la cárcel de Villavicencio caracterizados como población LGBTI. Participaron en esta investigación cuatro presos de los 16 que están identificados dentro del establecimiento penitenciario y carcelario como integrantes de la comunidad LGBTI. Dos mujeres y dos hombres. Todos con nivel de educación básica primaria; sus edades oscilaban entre los 20 y 21 años en los

TE Rodríguez Silva Rubén (oficio 131.EPMSC VILLV 3398 AYT junio 12 de 2015). varones, y 27 y 28 años en las mujeres, según su sexo biológico. Fueron judicializados por delitos como homicidio, hurto y estupefacientes. Las entrevistas se realizaron con la autorización del director del centro de reclusión y de los internos participantes.

Los criterios para incluir los participantes al estudio fueron la referencia por parte de la psicóloga de la institución, quien tiene comunicación constante con la población LGBTI, tanto de los pabellones de hombres como del Centro de Reclusión de Mujeres, y la aceptación expresa de los participantes al indicarles el objeto de estudio de la investigación. Quienes se negaron a participar de la investigación adujeron no querer hacerlo por no tener interés en los resultados de esta.

\section{Fuentes de recolección de la información}

Dentro de las fuentes primarias utilizadas se diseñó, elaboró y aplicó una entrevista dirigida a cuatro personas LGBTI privadas de la libertad, recluidas en la cárcel de Villavicencio. Así mismo, se aplicó una entrevista a la líder de la comunidad LGBTI en la misma ciudad y a la psicóloga del establecimiento carcelario. Como fuentes secundarias se recurrió a libros, estudios, monografías, jurisprudencia y revistas especializadas en el tema.

\section{Procedimiento}

El grupo de investigación se documentó sobre las características físicas y psicológicas de las personas transgénero, especialmente transexuales; presentó derechos de petición al director de la prisión con la finalidad de que permitiera a los internos colaborar con la investigación.

Se programaron tres entrevistas, una de aplicación colectiva a los cuatro participantes, quienes fueron informados y autorizados previamente por el director, y se reunieron en una de las oficinas administrativas del centro penitenciario. Otra entrevista a la líder de la comunidad LGBTI en la ciudad de Villavicencio, quien es una mujer trans, y una última entrevista a la psicóloga del penal en estudio. 


\section{B. Referente conceptual}

\section{Diferencias físicas y psicológicas de las personas transexuales}

Al iniciar la investigación se estudiaron las características físicas y psicológicas de las personas transexuales para lograr distinguirlas de las transgénero, travestis, drag-queens, homosexuales y lesbianas. Hay que entender que "el travestismo, la transexualidad y el transgenerismo son diferentes en cuanto a sus presupuestos e implicaciones" (Vendrell, 2012, p. 118).

La transexualidad es una realidad que genera diversos puntos de vista entre los expertos. De acuerdo con Atienza y Armanza (2014) desde 1980 la Organización Mundial de la Salud la cataloga como un "trastorno de identidad de género" en The ICD-10 classification of mental and behavioural disorders: diagnostic criteria for research. No obstante, en el mes de mayo de 2013 la American Psychiatric Association publicó la quinta edición del Diagnostic and statistical manual of mental disorders, DSM-5 donde excluyó la transexualidad de la lista de trastornos mentales, o trastorno de identidad de género.

Por otro lado, psiquiatras como Rafael Salín (2015) están realizando investigaciones donde algunos de sus resultados arrojan que la homosexualidad y la transexualidad son una "paradoja evolutiva natural"; para este autor existe "homosexualidad" entre algunos animales y partiendo de estas observaciones afirma que dentro de la teoría general evolutiva hay explicaciones para integrar la diversidad sexo-genérica.

El doctor Salín (2008) en el artículo "La comprensión transexual de la relación entre el cuerpo y la mente" revisa los conceptos que se vinculan con el estilo de vida de las personas transgénero, así como la terminología empleada allí, explicando las diferencias entre transexuales, travestis y drag-queens.

[...] la persona transexual (TS) es un individuo que se percibe en un cuerpo del sexo opuesto al de su género biológico somático o de apariencia (fenocopia). Es decir, se percibe como una mujer que está en un cuerpo de un hombre, o viceversa. Al primer tipo se le conoce como mujer transexual y al segundo, como hombre transexual... La transexualidad no está directamente relacionada con la orientación sexual, la cual tiene que ver con la atracción por las personas de un género en particular (hetero y homosexual) o por ambos (bisexual).

El término transgénero tiende a utilizarse como sinónimo de transexual, pero no es equivalente, ya que el primero abarca todos los estilos de vida en los cuales se realiza un cambio, definitivo o momentáneo, del género biológico (genético) al opuesto, esto es, engloba a todas las situaciones de transexualidad, travestismos, drag-queen, etcétera (Salín, 2008, p. 88).

En las sociedades a los niños y niñas les enseñan unos patrones de crianza dependiendo del órgano sexual con el que nacieron, y esa situación los hace sentirse mujer $\mathrm{u}$ hombre; no obstante, las personas transgénero no se identifican con el género que les correspondería de acuerdo con su órgano genital, por ese motivo, deciden en algún momento de su vida, vestirse o comportarse como las personas del género opuesto y, en los casos radicales, realizarse la cirugía de cambio de órganos genitales, esto incluye, desde luego, el cambio de identidad civil. "El sexo funciona orientando y legitimando determinados juegos socioculturales que serán posibles y esperados: la reproducción como finalidad de la relación sexual, las identidades diferenciadas y jerarquizadas entre hombre $y$ mujer, la familia heterosexual como institución social básica" (Martínez-Guzmán, 2012, p. 176). Indica el Protocolo de Intervención Psicológica en la Transexualidad aplicado por el Colegio Oficial de Psicólogos de Las Palmas de la Comunidad Autónoma de Canarias, España, que

[...] es importante tener claro la diferencia entre orientación sexual e identidad sexual. 
La orientación sexual es la atracción física hacia una persona por razón de su sexo (que puede ser heterosexual $u$ homosexual básicamente), mientras que la identidad sexual es el rol social que se adopta, sea este el esperado o no por su sexo asignado. El homosexual se siente a gusto con su propio sexo biológico y con todos sus caracteres primarios y secundarios; diferenciándose del heterosexual por su orientación sexual. Así, podemos encontrar transexuales homosexuales y heterosexuales (Bordón y García, 2001, p. 4).

El sociólogo Javier Rubio Arribas sostiene

[...] que no hay que confundir la transexualidad con el travestismo -ser travesti, drag's queens o drag king- ya que estas últimas personas utilizan indumentaria del sexo opuesto, pero no rechazan su cuerpo ni sienten la necesidad de modificarlo -no tienen conflictos con su identidad sexual-. Por tanto, podemos afirmar que los y las personas transexuales no son personas "disfrazadas" del otro sexo, muy al contrario, son personas que implican en este cambio la estabilidad de su vida social y laboral/profesional, arriesgan su salud y hasta su vida por lograr la armonía deseada a la que aspiran y comprometen seriamente su bienestar futuro ya que estamos en una sociedad aún muy intolerante, especialmente con las cuestiones relativas al sexo (2009, pp. 1-2).

Ahora bien, biológicamente los sexos están clasificados en masculino y femenino ${ }^{2}$, no obstante en Australia la Comisión Australiana de Derechos Humanos en un documento de trabajo enumera hasta veinte identidades de género (CampilloVélez, 2013). En este mismo país se reconoció jurisprudencialmente el "sexo neutro".

La feminidad ahora está conformada por quienes nacieron biológicamente mujeres, pero también hay mujeres transexuales y mujeres transgénero. Se recomienda el artículo de Janet Noseda Gutiérrez "Muchas formas de transexualidad: diferencias de ser mujer transexual y de ser mujer transgénero" (2012).
[...] uno de los casos que más sorprendió a la comunidad internacional en los últimos años fue el de Norrie May-Welby, australiano de 48 años que fue operado como un transexual, y posteriormente, ante su negativa de vivir como mujer -por no sentirse identificadafue oficialmente declarado como [de] "sexo neutro", su certificado de nacimiento fue reemplazado por uno que señala "sexo no especificado” (Santa María, 2013).

\section{Criterios de distribución de los internos en el sistema penitenciario colombiano}

El artículo 11 de la ley 1709/2014 que modificó el artículo 20 de la ley 65/1993 declara que los establecimientos de reclusión se clasifican en cárceles de detención preventiva, penitenciarías, casas para la detención y cumplimiento de pena por conductas punibles culposas cometidas en accidente de tránsito o en ejercicio de toda profesión u oficio, centros de arraigo transitorio, establecimientos de reclusión para inimputables por trastorno mental permanente o transitorio con base patológica y personas con trastorno mental sobreviniente, cárceles y penitenciarías de alta seguridad, cárceles y penitenciarías para mujeres, cárceles y penitenciarías para miembros de la Fuerza Pública y colonias.

Los centros de reclusión de mujeres son los establecimientos destinados para la detención y descuento de la pena impuesta a mujeres infractoras. Según la ley 65/1993 en el título II artículo 26, deberán contar estos establecimientos con una infraestructura idónea para mujeres gestantes: mantenimiento de condiciones dignas que no alteren ni afecten su estado de embarazo durante la permanencia en estos centros de reclusión. También, habrá un ambiente adecuado para madres lactantes y sus hijos menores de tres años que al momento de ingresar a estos centros, existan o durante su estadía nazcan.

Cabe señalar que la ley no tiene un trato diferenciado (condiciones estructurales) respecto de la población transgénero ni en general con la población LGBTI en las cárceles. El Estableci- 
miento Penitenciario y Carcelario de Villavicencio se considera de mediana seguridad y alberga tanto a hombres como a mujeres en detención preventiva y también a condenados, siendo el único presidio con estas características en esta ciudad.

Ahora bien, los criterios para clasificar a los internos están consagrados en el artículo 63 de la ley 65/1993, donde se prescribe que los internos en los centros de reclusión serán separados por categorías, atendiendo a su sexo, edad, naturaleza del hecho punible, personalidad, antecedentes y condiciones de salud física y mental. Los detenidos estarán separados de los condenados, según su fase de tratamiento, los hombres de las mujeres; los primarios de los reincidentes; los jóvenes de los adultos; los enfermos de los que puedan someterse al régimen normal.

La clasificación de los internos por categorías se hará por las mismas juntas de distribución de patios y asignación de celdas, para estos efectos se considerarán no solo las pautas aquí expresadas, sino la personalidad del sujeto, sus antecedentes y conducta.

El sociólogo Daniel Acosta (1996) de la Oficina de Planeación del Inpec en el documento Sistema integral de tratamiento progresivo penitenciario, sostiene que el medio penitenciario y carcelario ha tenido como grave problema la promiscuidad, la cual se intenta solucionar de diversas formas. Afirma que se busca tener cárceles por género, por situación jurídica, proteger los grupos expuestos al impacto de la subcultura carcelaria, etc. Considera que la apertura de la ley 65/1993 crea espacios teórico-prácticos para fomentar nuevos caminos, entre otros hacia la clasificación y selección de los reclusos.

A la luz de estos lineamientos legales, el Establecimiento Penitenciario y Carcelario de Villavicencio cuenta con el Pabellón Colombia, Pabellón Santander y reclusión de mujeres, pero carece de pabellones especiales tanto para personas transexuales como comunidad LGBTI.

\section{Derechos de las personas transexuales privadas de la libertad}

En Colombia estar sometido a un juicio donde el juez decide que la persona debe estar recluida de forma preventiva en un centro carcelario mientras se lleva a cabo la investigación y el juzgamiento, es una suspensión válida al derecho de libertad. A la persona debe respetársele su dignidad humana y debe ser tratada según el principio de presunción de inocencia.

El sujeto condenado por la comisión de un delito ve suspendidos muchos de sus derechos, entre ellos, los derechos políticos y lógicamente el derecho a la libertad, sin embargo, nunca perderá su dignidad humana ni sus derechos fundamentales, como el libre desarrollo de la personalidad. Por tal motivo, el grupo de investigación decidió indagar sobre la posición de la jurisprudencia de la Corte Constitucional respecto a los derechos que tienen las personas transexuales privadas de la libertad.

En la sentencia T-062/2011 la Corte Constitucional analizó el caso de Erick Yosimar Ortiz Lastra, quien interpuso una acción de tutela contra el Establecimiento Penitenciario de Mediana Seguridad de Yopal (Casanare). Los hechos que suscitaron la acción de tutela consistieron en que el accionante Erick, al ingresar a dicha prisión en ejecución de la pena, hizo pública su condición de "gay transexual". A esto se suma que dejó crecer su cabello y comenzó a usar productos de maquillaje y accesorios dentro del establecimiento carcelario, que consideraba acordes con su identidad sexual. Manifestó el accionante que por hacer pública su condición y mostrar su comportamiento, comenzó a ser discriminado de manera violenta por parte de la guardia penitenciaria. Señaló que fue objeto de burla $e$ irrespeto por parte del personal de vigilancia y custodia y menciona que un miembro de la guardia lo amenazaba con cortarle el cabello y dejarlo calvo, para que fuera como los demás.

Debido a estas conductas de la guardia de la cárcel, el actor interpone una acción de tutela por 
desconocimiento de sus derechos fundamentales, con el fin de que se le ordenara a los funcionarios del Inpec que se abstuvieran de continuar con los tratamientos expuestos y le restituyeran y permitieran usar los objetos decomisados.

En la contestación de la demanda, el director del establecimiento carcelario envió un comunicado justificando los actos expresados por el accionante, manifestó que en el acuerdo 0011/1995, artículo 38, estaban las prohibiciones de los internos relacionadas con la higiene personal, entre estas la de uso de barba o cabello largo. En ese sentido, la obligación de portar el pelo corto por parte del accionante se derivaba de dicha prescripción; también citó el artículo 48 del mismo reglamento, donde dice que dentro de los elementos cuyo ingreso y tenencia por parte de los internos están prohibidos, se encuentran los "brazaletes, pelucas, maquillaje femenino, prendas femeninas, gabanes y abrigos" (Corte Constitucional, 2011, p. 6). Agregó que, en relación con los presuntos maltratos y burlas, no conocía informes sobre ese particular, distintos a los que el personal de guardia expresa "no haber tenido tratos diferentes al estrictamente necesario sin degradar la condición de este tipo de internos" (Corte Constitucional, 2011, p. 6).

En primera instancia, el Juzgado Único Penal del Circuito Especializado de Yopal, declaró procedente la acción de tutela. Sin embargo, el director del penal apeló el fallo de primera instancia y en el fallo del 20 de agosto de 2010, la Sala Única de Decisión del Tribunal Superior de Yopal revocó la sentencia impugnada y negó el amparo de los derechos fundamentales.

Antes de que la Corte Constitucional revisara la sentencia de tutela, el accionante fue trasladado al centro penitenciario en Santa Rosa de Viterbo, y en este lugar logró un tratamiento adecuado para que sus derechos fundamentales no se vieran afectados. No obstante, la Corte sin importar que el hecho había sido superado, amparó los derechos fundamentales del actor y consideró que sería necesario conceder la protección de los derechos invocados, a fin de revocar la decisión de segunda instancia, la cual es contraria al contenido y alcance de las garantías constitucionales.

La Corte estimó que las citadas limitaciones y restricciones que los centros penitenciarios ejecutan deben cumplir con ciertas condiciones, como requisitos de necesidad, razonabilidad y proporcionalidad. Entonces, consideró que dichas limitaciones y restricciones desconocen la prohibición constitucional de discriminación en razón de la identidad u opción sexual, y afectan el derecho fundamental y principio constitucional de la dignidad humana, el cual conlleva la facultad del sujeto de optar por una identidad sexual y ejercer comportamientos y actitudes derivados de la misma.

Este ha sido el sentido de la jurisprudencia al indicar que es evidente que aunque los derechos fundamentales de los presos como la libertad personal y la libertad de locomoción se encuentran suspendidos, otros derechos fundamentales como la intimidad personal y familiar, libre desarrollo de la personalidad y libertad de expresión, así como la dignidad humana, la vida, la salud, la integridad personal, la igualdad, la libertad religiosa, el derecho al reconocimiento de la personalidad jurídica, al debido proceso y de petición, no pueden ser limitados de ninguna manera por las autoridades penitenciarias y carcelarias. A su vez, la Corte Constitucional en sentencia T-213/2011 del magistrado Gabriel Eduardo Mendoza, determinó que los derechos fundamentales de los reclusos se clasifican en tres grupos:

Primer grupo: derechos intocables. Derechos inherentes a la naturaleza humana que no pueden suspenderse ni limitarse por el hecho de que su titular se encuentre en establecimiento penitenciario (derecho a la vida, la dignidad humana, la integridad personal, la igualdad, libertad religiosa, debido proceso y petición). Aquí observamos que de este grupo aplicado a las personas transexuales recluidas se vulneran principalmente derechos tales como la dignidad humana, la integridad personal, la igualdad y el derecho de petición. 
Segundo grupo: derechos suspendidos. Son consecuencia lógica y directa de la pena impuesta (la libertad personal, la libre locomoción, entre otros).

Tercer grupo: derechos restringidos. Son el resultado de la relación de sujeción del interno para con el Estado; dentro de estos encontramos los derechos al trabajo, a la educación, a la intimidad personal y familiar, de reunión, de asociación, libre desarrollo de la personalidad y libertad de expresión. Por tanto, la relación de especial sujeción que existe entre las personas privadas de la libertad y el Estado, no es otra cosa que "una relación jurídica donde el predominio de una parte sobre la otra no impide la existencia de derechos y deberes para ambas partes" (Corte Constitucional, 2011, p. 21).

Por otro lado, la Oficina del Alto Comisionado para los Derechos Humanos (OACDH) (1977) propuso unas reglas mínimas para el tratamiento de los reclusos ${ }^{3}$, donde se estipulan las categorías que deberían tenerse en cuenta para separar los presos unos de otros dependiendo de sus características en particular.

Separación de categorías: los reclusos pertenecientes a categorías diversas deberán ser alojados en establecimientos distintos o en diferentes secciones dentro de los establecimientos, según su sexo y edad, sus antecedentes, los motivos de su detención y el trato que corresponda aplicarles. Es decir que: (i) los hombres y las mujeres deberán ser recluidos, hasta donde fuere posible, en establecimientos diferentes; en un establecimiento en el que se reciban hombres y mujeres, el conjunto de locales destinado a las mujeres deberá estar completamente separado; (ii) los detenidos en prisión preventiva deberán ser separados de los que están cumpliendo condena; (iii) las personas presas por deudas y los demás condenados a alguna forma de prisión por razones civiles debe-

Estas fueron adoptadas por el Primer Congreso de las Naciones Unidas sobre Prevención del Delito y Tratamiento del Delincuente, celebrado en Ginebra en 1955, y aprobadas por el Consejo Económico y Social en sus resoluciones 663C (XXIV) de 31 de julio de 1957 y 2076 (LXII) de 13 de mayo de 1977. rán ser separadas de los detenidos por infracción penal; y (iv) los detenidos jóvenes deberán ser separados de los adultos (OACDH, 1977).

Otro de los derechos que ha sido reconocido a los miembros de la comunidad LGBTI recluidos en establecimientos carcelarios es a la visita íntima de su pareja (Corte Constitucional, sentencia T-559 del 22 de agosto de 2013).

En este orden de ideas, la propuesta que se quería validar con la investigación base de este artículo era identificar la necesidad de implementar un nuevo criterio de separación en la cárcel de Villavicencio, donde se diferenciaran los pabellones de reclusión para mujeres, hombres y personas transexuales.

\section{Resultados y discusión}

A pesar de que el objeto de estudio de la investigación era el ejercicio de los derechos de las personas transexuales recluidas en el Establecimiento Penitenciario y Carcelario de Villavicencio, Meta, se encontró que, de acuerdo con las condiciones físicas y psicológicas de los internos que accedieron a la entrevista, ninguno era transexual. Hasta el momento, ninguno se ha realizado cirugía alguna para reasignar su sexo, tanto hombres como mujeres están conformes con sus órganos genitales biológicos, no obstante, dos de los participantes, un hombre y una mujer, visten prendas del sexo contrario, por lo que según los conceptos del doctor Rubio (2009) analizados en la introducción, ellos serían travestis, y los otros dos participantes, que no gustan de ponerse prendas del sexo contrario pero sí tienen inclinación sexual por personas de su mismo sexo, serían una mujer y un hombre homosexual.

Cabe indicar que "las cirugías son procesos de transformación corporal muy importantes para algunas personas trans, en la medida que tienen efectos a nivel legal, por ejemplo, el cambio de la denominación de $\mathrm{F}$ o $\mathrm{M}$ en el documento de identidad" (Lasso, 2014, p. 119). 
Tabla 1. Entrevistados

\begin{tabular}{lcll}
\hline \multicolumn{1}{c}{ Nombre } & Edad & Sexo & Género y tendencia sexual \\
\hline Alix Tatiana & 27 & Femenino & Mujer homosexual \\
Yadira, alias Andrés & 28 & Femenino & Hombre travesti homosexual \\
Pedro José & 20 & Masculino & Hombre homosexual \\
Jorge Enrique, alias Camila & 21 & Masculino & Mujer travesti homosexual \\
\hline
\end{tabular}

Nota: los nombres han sido modificados para proteger la identidad y la intimidad de los participantes en el estudio.

Fuente: elaboración propia.

En las entrevistas se observó que el léxico utilizado por los participantes demuestra que cuentan con una educación básica, a pesar de que se autorreconocen como personas LGBTI no definen con claridad su identidad, algunos son llamados por su nombre de pila, pero Yadira y Jorge Enrique emplean alias con nombres del sexo opuesto, por cuanto se sienten un hombre y una mujer respectivamente. En el presente escrito se hará referencia a cada uno de los entrevistados de acuerdo con su género y no por su sexo, respetando su libre desarrollo de la personalidad.

\section{La historia de Pedro José, Camila, Alix Tatiana y Andrés}

Las personas recluidas en el Establecimiento Penitenciario y Carcelario de Villavicencio que participaron en la presente investigación y forman parte del pabellón de hombres son Pedro José y Jorge Enrique (el nombre femenino de Jorge Enrique es Camila, viste prendas femeninas y le gusta que la traten como mujer); del pabellón de las mujeres colaboraron Alix Tatiana y Yadira (quien usa el nombre masculino de Andrés y viste con prendas masculinas).

Camila aseguró que por su condición de travesti le es difícil encontrarse en el pabellón de hombres, Pabellón Colombia; allí vive discriminación diariamente, no por parte de la guardia sino de los compañeros. Menciona que no quiere que le "tiren papa", le peguen con el balón o le hagan mofas. Le gusta vestir de mujer porque se siente bien así, a pesar del maltrato del que es víctima.
Asegura que no está acostumbrada a este trato discriminatorio porque cuando era libre y estaba en la calle recibía mayor respeto. Afirma Camila que en las audiencias se refieren a ella por su nombre de pila varonil. Se le sugirió hacer el cambio de nombre en la cédula de ciudadanía para que el trato fuera acorde con su género, frente a lo cual se mostró interesada.

Pedro José es de género masculino con tendencia sexual homosexual y se encuentra recluido en el pabellón de hombres junto con Camila. Trabaja todos los días y al igual que Camila, sostiene que los demás internos se han acostumbrado a convivir con ellos.

Manifiesta Camila que los guardias muchas veces no dejan ingresar elementos femeninos como polvos o ropa de mujer al pabellón donde ella paga su condena, que es el Pabellón Colombia. Asegura que tener que compartir el pabellón con hombres es bueno porque puede tener relaciones sentimentales, además un pabellón solo para personas transexuales, opina, podría complicar la convivencia.

Pedro José expresa que en su celda convive con siete personas, que vive bien y se siente aceptado por sus compañeros de celda, tiene pareja y lleva una vida normal. Él y Camila aseveran que cuando han sido objeto de discriminación por parte de otros presos, no han denunciado el hecho ante el Inpec para no mostrarse débiles, las acciones las toman de manera personal. Concluyen que, a pesar de la discriminación 
la guardia es muy tolerante, neutral cuando surgen conflictos. Para Camila si la guardia no les ayudara, ya ellos ni existirían.

Yadira nació mujer y viste prendas masculinas, le gusta que la llamen Andrés. Andrés se encuentra recluido en el Pabellón de las Mujeres. Considera que recibe discriminación por parte de muchas internas que no aceptan vivir con homosexuales. Señala que a veces tiene choques con las compañeras que intentan hacerlo sentir mal.

A Andrés sí le gusta la idea de tener un pabellón solamente para personas travestis y homosexuales, de manera que si tiene pareja, pueda vivir con ella en el mismo lugar, sin necesidad de incomodar a las demás reclusas. A él, en especial, le sucede que se siente cohibido para expresar el cariño a su pareja, por el rechazo, las mofas y las humillaciones.

Alix Tatiana, quien está recluida en el Pabellón de Mujeres, tiene hijos pero su inclinación sexual es lésbica. Confirma lo dicho por Andrés y asegura que es objeto de discriminación por parte de las compañeras y también de sus familiares.

En este orden de ideas, los participantes no denuncian malos tratos por parte de los guardianes del Inpec sino de los demás compañeros de prisión. Con el paso del tiempo la convivencia se ha hecho más fácil y las situaciones de discriminación, rechazo, odio y maltrato han mermado, por lo que se sienten más tolerados que antes.

\section{Una mirada desde el liderazgo de las comunidades LGBTI en Villavicencio}

Angélica María Caicedo Bautista es una líder de la comunidad LGBTI que lleva 37 años viviendo en Villavicencio, tiene tres hijos adoptivos, es casada y fue la primera transgenerista que sacó su cédula como mujer en Colombia; ha trabajado con derechos humanos y con la Personería ${ }^{4}$ de la ciudad.

$4 \quad$ El artículo 118 de la Constitución Política refiere las personerías municipales como uno de los órganos que ejerce el Ministerio Público en Colombia.
Cuenta Angélica que entre las mayores quejas que recibe de personas de la comunidad LGBTI recluidas en cárceles, están las que se vinculan a las dificultades en la convivencia, a la ausencia de tolerancia, por esa razón acuden a ella buscando protección. Para la líder sí sería conveniente que existiera un pabellón especial para los miembros de la comunidad LGBTI, así podrían recibir mayor seguridad y protección en el cumplimiento de la pena, y tener una mejor calidad de vida. Sin embargo, uno de los problemas que advierte Angélica para la creación de pabellones o cárceles especiales es que no todos los hombres y mujeres homosexuales aceptan su condición de homosexualidad, debido, en gran medida, a prejuicios sociales muy arraigados, tales como el machismo. Además, se pregunta de qué serviría una prisión especial si todavía hay miembros de la policía que son homofóbicos. Considera que se necesitan capacitaciones al Inpec, Policía y Ejército Nacional, para que no cometan atropellos en contra de la comunidad ${ }^{5}$.

\section{Entrevista a la psicóloga del Estable- cimiento Penitenciario y Carcelario de Villavicencio}

Se entrevistó a la psicóloga del centro penitenciario en estudio, el objetivo era determinar desde su trabajo cómo es la convivencia de la comunidad LGBTI, sobre todo la comunidad transexual recluida en tales instalaciones.

Explica la psicóloga que

[...] no existen diferencias al interior del centro carcelario y penitenciario con la comunidad LGBTI, son internos e internas que están en las mismas condiciones que todo el personal, deben cumplir con el reglamento del régimen interno, viven los procesos de resocialización, se les respeta su dignidad humana, sus derechos fundamentales, y los demás internos

5 Aunque los resultados de la investigación sean contrarios, las declaraciones de la líder de la comunidad LGBTI, Angélica María Caicedo Bautista, se incluyen en este estudio, aclarando que son exclusivamente responsabilidad de ella. 
les respetan a ellos sus condiciones también, por lo que existe una convivencia sana al interior del penal.

Dice que de ninguna manera se ha tenido abuso por parte del personal interno ni de funcionarios, ni ha habido denuncias al respecto, debido a que es una comunidad a quien se le respeta los derechos fundamentales, los derechos humanos, su dignidad humana dentro del centro de reclusión y se cumple con eficacia y eficiencia cada uno de los procesos a llevar a cabo dentro del penal.

Sostiene que no hay un pabellón especial para albergar a estas personas, sin embargo los internos pertenecientes a la comunidad LGBTI se mantienen ocupados en algunos procesos de resocialización que la trabajadora social maneja dentro del establecimiento. El cónsul de derechos humanos está pendiente del bienestar de estas personas, lo mismo dice del cuerpo de custodia y vigilancia; el personal de funcionarios también mantiene vigilancia especial en pro de una mejora continua, se miran las debilidades y fortalezas para cada día optimizar los procesos y que sea efectiva su inclusión social.

Para la profesional sí debería haber un pabellón especial para la comunidad LGBTI, debido a que mejorarían los procesos de resocialización y atención básica en cada uno de los ejes fundamentales de que dispone el establecimiento, $y$ quizá mejores resultados en el proceso de inclusión social. A pesar de que en la actualidad no existe el pabellón especial se realizan diferentes campañas, tanto con el personal de internos como el de funcionarios que laboran en el establecimiento.

Con el propósito de crear un ambiente de respeto y tolerancia dentro del mismo, se ejecutan campañas de entrenamiento para evitar que mediante lenguajes y comportamientos inadecuados tanto de los internos como a veces de algunos funcionarios puedan vulnerar los derechos. En la directiva 0010/2011 el Inpec impartió instrucciones para garantizar el respeto y protección a la población de internas e internos LGBTI en las cárceles del país.
Así las cosas, la psicóloga sostiene que a las personas transexuales sí se les deja utilizar su vestuario, se pueden peinar como quieran verse, utilizan su maquillaje... no obstante, sí se nota la diferencia entre los internos por las características de las personas que manejan otra conducta y otros comportamientos. Sin embargo, para evitar la discriminación, rechazo, odio y maltrato, el centro carcelario trata de propiciar la tolerancia, realizando campañas de sensibilización y protección hacia este tipo de personas.

A veces se observan conductas no apropiadas contra esta población, pero con las campañas y las actividades que se llevan a cabo se evidencia que sí se produce un impacto positivo y llega a minimizarse este tipo de comportamientos hostiles en los internos hacia este colectivo, propiciando un ambiente de respeto y tolerancia hacia la comunidad LGBTI.

Ahora bien, aunque Camila y Pedro José no ven la necesidad de tener un pabellón exclusivo para las personas de la comunidad LGBTI, pues afirman que la convivencia con la población heterosexual es buena y las circunstancias les permiten tener pareja, distinto piensan Alix Tatiana y Andrés, quienes quisieran un patio o pabellón para ellos solos, propuesta que apoya la psicóloga del centro penitenciario, quien aduce que un patio o pabellón exclusivo para población LGBTI permitiría mejorar sus procesos de resocialización.

El grupo de investigación deduce que, por ahora, no es menester un pabellón exclusivo para personas transexuales en la cárcel de Villavicencio, por un lado, no hay recluidas allí personas con estas características y aunque hay presencia de homosexuales y travestis, se comprobó que ellos han logrado hacerse respetar entre los compañeros y guardias, quienes los toleran. Se pone en evidencia la necesidad de seguir adelantando capacitaciones con los internos para que la discriminación hacia la población LGBTI sea nula.

Este resultado es similar al encontrado en la investigación de Margarita Camacho Zambrano 
(2007): "Cuerpos encerrados, cuerpos emancipados. Travestis en el ex penal García Moreno", donde se constató que en la cárcel ecuatoriana García Moreno existe tolerancia por la presencia de personas transexuales, quienes con su femineidad "permiten que el comportamiento de los hombres presos, se desenvuelva libre de prejuicios homosexuales" (Mejía, 2013, pp. 27-28).

La lucha de la comunidad LGBTI para que las personas transexuales sean aceptadas por la sociedad como seres humanos que optaron por cambiar el sexo con el que nacieron, ha sido de años y a costa de muchos sacrificios, sin embargo, falta mucho porque el respeto hacia estas personas sea una realidad. Tal es la situación que contó Angélica María Caicedo, líder de la comunidad LGBTI en Villavicencio.

Se observan los avances del Estado en la capacitación de sus funcionarios en la protección de los derechos de la comunidad LGBTI. Según testimonios de los participantes en el estudio, el personal del Inpec es más tolerante, incluso más que los mismos reclusos, con quienes comparten este momento de su vida.

En las entrevistas se observó cómo los participantes resisten situaciones de burlas, restricciones y demás actos de discriminación sin que se quejen ante las autoridades respectivas, dadas las circunstancias de confinamiento en las que viven, no obstante se reporta el aumento de los derechos y garantías para la comunidad LGBTI recluida en cárceles en el país.

La Defensoría del Pueblo de Colombia en el V Informe sobre Derechos Humanos Sistema Penitenciario dice que el Código Penitenciario y Carcelario señaló que los sindicados y los condenados tienen derecho a recibir visitas de familiares y amigos. La visita íntima, según el artículo 112 de la ley 65/1993, es regulada por el reglamento general, que es el acuerdo 0011/1995, según principios de higiene, seguridad y moral. Cada establecimiento debe habilitar un lugar especial para la visita íntima. Existe también en Colombia la visita íntima homosexual, la cual fue regulada por el Inpec en el año 2003, acatando la sentencia T-499/2003 proferida por la Corte Constitucional.

Antes de 1991, la mujer reclusa no tenía derecho a la visita conyugal porque las autoridades penitenciarias presumían que podía quedar embarazada y, por lo tanto, obtendría la libertad. Después de promulgada la Constitución de 1991, las internas fueron conquistando este derecho mediante la acción de tutela (Ramos, 2007).

\section{Conclusiones}

La investigación arroja que a pesar de que el Estado colombiano hace un esfuerzo enorme por cumplir los tratados internacionales de derechos humanos como la Convención Americana sobre Derechos Humanos y la Constitución Política ${ }^{6}$ dentro de la actividad que ejerce el Inpec, quien tiene bajo su administración el sistema penitenciario en la nación, la discriminación en los centros penitenciarios y carcelarios contra la población transgenerista aún está latente. En la prisión de Villavicencio todavía existen conductas que se perciben como actos de discriminación contra esta población, no tanto por los miembros del Inpec sino por parte de los demás internos.

El hecho de que el Estado no permita el ingreso de maquillaje y prendas de vestir, según la identidad de género de los reclusos, como el caso de las mujeres transexuales y travestis, coarta el libre desarrollo de la personalidad, por ello la Corte Constitucional ha ordenado al Inpec autorizar el ingreso y uso de este tipo de elementos para que las personas transexuales y travestis puedan lucir como desean, y ha hecho hincapié en que hay derechos fundamentales que no se pueden restringir a pesar de la situación de reclusión.

\footnotetext{
El principio constitucional de la dignidad humana (artículo 1). Los derechos fundamentales que prohíben la tortura, tratos o penas crueles, inhumanos o degradantes (artículo 12); que consagran la igualdad (artículo 13); la intimidad personal y familiar (artículo 15); el libre desarrollo de la personalidad (artículo 16) y el debido proceso (artículo 29)
} 
Es indispensable que en cada centro carcelario se apliquen efectivamente las orientaciones dadas por la Corte Constitucional y las nuevas resoluciones del Inpec, donde se permite la entrada de maquillaje y otros objetos que puedan ser importantes para los reclusos que son transgeneristas así como la visita íntima, en pro de la salvaguarda sus derechos constitucionales.

Se concluye que en el Establecimiento Penitenciario y Carcelario de Villavicencio no es necesaria la creación inmediata de un pabellón para personas transexuales, pues, como tal, no hay presos que pertenezcan a esta población, hay personas con tendencia homosexual y travestis, mas no transexuales, aunque es importante que se sigan realizando campañas de sensibilización entre la comunidad recluida para que sea más tolerante con la población LGBTI.

Estas capacitaciones deben ser impartidas también a las personas de la comunidad LGBTI, al evidenciarse en las entrevistas que no tienen claridad sobre su identidad y, por tanto, sobre sus derechos.

\section{Referencias}

Acosta, M. D. (1996). Sistema integral de tratamiento progresivo penitenciario. Bogotá: Instituto Nacional Penitenciario y Carcelario. Disponible en: http://www.inpec.gov. co/portal/page/portal/Inpec/Institucion/ Estudios\%20Penitenciarios/1.2.pdf

Atienza, M. E. \& Armaza, A. J. (2014). La transexualidad: aspectos jurídico-sanitarios en el ordenamiento español. Salud Colectiva, 10(3), pp. 365-377. Disponible en: http://www.redalyc.org/articulo. oa?id $=73138581007$

Bordón, R. \& García, L. (2001). Protocolo de intervención psicológica en la transexualidad. Hojas Informativas de los Psicólogos de Las Palmas, 4(43). Disponible en: http:// pendientedemigracion.ucm.es/info/rqtr/ biblioteca/Transexualidad/protocolo_de intervencion_psicologica_transexual.pd $\bar{f}$
Campillo-Vélez, B. E. (2013). La ideología de género en el derecho colombiano. Díkaion, 22(1), pp. 13-54. Disponible en: http:// search.proquest.com/docview/1532987 890 ? accountid $=44394$

Congreso de la República de Colombia. (1991). Constitución Política. Bogotá: Congreso de la República de Colombia.

Corte Constitucional de Colombia. (2003). Sentencia T-499. M. P.: Álvaro Tafur Galvis.

Corte Constitucional de Colombia. (2011). Sentencia T-062. M. P.: Luis Ernesto Vargas Silva.

Corte Constitucional de Colombia. (2011). Sentencia T-213. M. P.: Gabriel Eduardo Mendoza Martelo.

Corte Constitucional de Colombia. (2013). Sentencia T-559. M. P.: Luis Guillermo Guerrero Pérez.

Fernández, N. (2006). Salud psicológica y variables personales de las personas transexuales. Salamanca: Universidad de Salamanca. Disponible en: http://transexualia.org/wp-content/uploads/2015/03/ Sanidad_tesisrouco.pdf

Instituto Nacional Penitenciario y Carcelario. (1995). Acuerdo 0011. Por el cual se expide el reglamento general al cual se sujetarán los reglamentos internos de los establecimientos penitenciarios y carcelarios. Bogotá: Inpec.

Instituto Nacional Penitenciario y Carcelario. (2015). Oficio 131. EPMSC VILLV 3398 AYT junio 12. Bogotá: Inpec.

Lasso, R. A. (2014). Transexualidad y servicios de salud utilizados para transitar por sexos-géneros. Revista CES Psicología, 7(2), pp. 108-125. Disponible en: http:// revistas.ces.edu.co/index.php/psicologia/ article/view/2881

Ley 65 de 1993. Por la cual se expide el Código Penitenciario y Carcelario. Agosto 19. Diario Oficial, 40999. 
Ley 1709 de 2014. Por medio de la cual se reforman algunos artículos de la ley 65 de 1993, de la ley 599 de 2000, de la ley 55 de 1985 y se dictan otras disposiciones. Enero 20. Diario Oficial, 49039.

Martínez-Guzmán, A. (2012). Repensar la perspectiva psicosocial sobre el género: contribuciones y desafíos a partir de las identidades transgénero. Psicoperspectivas, 12(2), pp. 164-184. Disponible en: http:// www.scielo.cl/scielo.php?pid=S0718-692 42012000200009\&script $=$ sci_arttext

Mejía, F. (2013). ¿De qué reconocimiento hablamos en Colombia? Puede que seamos reconocidos por lo que no somos, pero no podemos reconocernos con lo que no sentimos. Tesis de maestría en Estudios Políticos. Bogotá: Pontificia Universidad Javeriana Facultad de Ciencias Políticas y Relaciones Internacionales. Disponible en: http://repository.javeriana.edu.co/ handle/10554/15298

Noseda, J. (2012). Muchas formas de transexualidad: diferencias de ser mujer transexual y de ser mujer transgénero. Revista de Psicología, 21(2), pp. 7-30. Disponible en: http:// www.revistapsicologia.uchile.cl/index.php/ RDP/article/viewFile/25835/27163

Oficina del Alto Comisionado para los Derechos Humanos. (1977). Reglas mínimas para el tratamiento de los reclusos. Disponible en: http://www.ohchr.org/SP/ProfessionaIInterest/Pages/TreatmentOfPrisoners.aspx

Ramos, P. (2007). Colombia. En: G. Escobar. V Informe sobre derechos humanos sistema penitenciario (pp. 159-176). Madrid: Federación Iberoamericana de Ombudsman, Trama Editorial. Disponible en: http://www. portalfio.org/inicio/repositorio/informes-fio/ informe_sistema_penitenciario.pdf

Rubio, J. (2009). Aspecto sociológico de la transexualidad. Revista Crítica de Ciencias Sociales y Jurídicas, 21. Disponible en: $\mathrm{http}: / /$ pendientedemigracion.ucm.es/info/ nomadas/21/fjrarribas.pdf

Salín, R. J. (2008). La comprensión transexual de la relación entre el cuerpo y la mente. Revista Trabajo Social, 18, pp. 86-99.

Salín, R. J. (2015). La diversidad sexo-genérica: un punto de vista evolutivo. Salud Mental, 38(2), pp. 147-153. Disponible en: http://www.inprf-cd.gob.mx/pdf/sm3802/ sm3802147.pdf

Santa María, D. R. (2013). Del género a la perspectiva de familia: elementos para una nueva propuesta. Díkaion, 22(2), pp. 273-302. Disponible en: http://www. redalyc.org/articulo.oa?id $=72031061005$

Vendrell, J. (2012). Sobre lo trans: aportaciones desde la antropología. Cuicuilco, 19(mayoagosto). Disponible en: http://www.redalyc. org/articulo.oa? id=35126359008 